\title{
Level of Snoring and Sleepiness Among Commercial Car Drivers in Southwestern Nigeria
}

\author{
Bright Otoghile $^{1,}$, Joseph Iraskeb Kuni ${ }^{2}$, Nasir Olakunle Ariyibi ${ }^{3}$, Confidence Otoghile ${ }^{4}$ \\ ${ }^{1}$ Department of Otorhinolaryngology, Federal Medical Centre, Yenagoa, Nigeria \\ ${ }^{2}$ Department of Otorhinolaryngology, Federal Medical Centre, Jalingo, Nigeria \\ ${ }^{3}$ Department of Community Medicine, Federal Medical Centre, Yenagoa, Nigeria \\ ${ }^{4}$ Department of Psychology, Obafemi Awolowo University, Ile-Ife, Nigeria
}

Email address:

otoghilebright@gmail.com (B. Otoghile)

${ }^{*}$ Corresponding author

\section{To cite this article:}

Bright Otoghile, Joseph IraskebKuni, NasirOlakunleAriyibi, Confidence Otoghile. Level of Snoring and Sleepiness Among Commercial Car Drivers in Southwestern Nigeria. Central African Journal of Public Health. Vol. 5, No. 1, 2019, pp. 13-16. doi: 10.11648/j.cajph.20190501.12

Received: November 20, 2018; Accepted: December 26, 2018; Published: January 21, 2019

\begin{abstract}
Snoring and sleepiness among commercial car drivers is an issue of public concern. Habitual sleepiness on the wheel is obviously associated with a high level of risk of accident and possible mortality to both drivers and passengers. Hence, this study aims to find the prevalence of snoring and level of sleepiness among commercial car drivers. This was a prospective community based study among intra-city commercial car drivers in a Southwestern part of Nigeria. The Berlin questionnaire and Epworth Sleepiness Scale were used to evaluate all participants for snoring and sleepiness respectively. The data obtained was analyzed using the statistical package for social sciences (SPSS) Version 20.0 software and the results were presented in descriptive format. A total of 105 drivers participated in the study and they were all males. Mean age of the drivers was $44.8 \pm 12.03$ years. The prevalence of snoring was $49 \%$ out which $30.7 \%$ had snoring as loud as talking and $16.3 \%$ had snoring that can be heard in adjacent rooms. Abnormal level of sleepiness was found in $35.2 \%$ of the drivers and $15.2 \%$ reported they had fallen asleep while driving. Snoring and abnormal level of sleepiness has been found to be prevalent among commercial car drivers.
\end{abstract}

Keywords: Snoring, Sleepiness, Drivers, Nigeria

\section{Introduction}

Snoring is defined as the low frequency sound produced by vibration of the upper airway walls during partial upper airway obstruction during sleep and sleep is defined as unconsciousness from which the person can be aroused by sensory or other stimuli $[1,2]$. Sleep is characterized by two distinct states; the Non-Rapid Eye movement (Non-REM) and Rapid Eye Movement sleep (REM). Non-REM and REM sleep alternate in 90- to 110-minute cycles. A normal sleep pattern has four to five cycles and the sleep cycle repeats itself throughout a night of sleeping with most obstructive events occurring during the REM sleep [3].

Habitual sleepiness while driving has been reported in $2 \%$ to $3 \%$ of drivers [4]. This is more significant among long distant drivers who drive through monotonous route daily which may predispose them to excessive sleepiness, especially during working hours. Excessive daytime sleepiness as a contributing factor to vehicular accidents, particularly among commercial truck drivers, has raised considerable concern [5]. Furthermore; habitually sleepy drivers have a significantly higher risk of car crashes. Accidents caused by sleepiness often are particularly serious because of lack of reaction to the collision [6]. Motor vehicle accidents are a major cause of death [5]. There are very few isolated studies on snoring and sleepiness among commercial drivers in Nigeria. In a sub urban city like Ile-Ife, Nigeria, a significant population of the residents depends on commercial vehicles as a means of transportation and there is a recent increase in road traffic accidents in different parts of 
Nigeria. Hence, this study aims to evaluate the level of snoring and sleepiness among commercial car drivers in IleIfe, Nigeria.

\section{Methods}

\subsection{Study Design}

This was a descriptive and cross sectional study.

\subsection{Study Location}

The study was done in Ile-Ife, a satellite town in Osun State and in the Southwestern Part of Nigeria. There are about 7 major commercial car parks in Ile-Ife and the Commercial vehicles in these parks are the major means of transportation in this sub urban community.

\subsection{Study Protocol}

Inclusion criterion was all intra-city commercial car drivers in Ile-Ife who gave consent and exclusion criteria were failure of the driver to give consent or failure to give consent for the spouse or partner to be interviewed. Drivers were met at the various car parks. Data on snoring and sleepiness were collected by administering the Berlin questionnaire and Epworth Sleepiness Scale respectively. The Berlin questionnaire consists of 10 questions divided into 3 categories. The first category includes questions regarding the loudness and frequency of snoring, whether the snoring bothered other people; the second refers to frequency of daytime sleepiness or sleepiness while driving; and the third refers to a history of high blood pressure and obesity (Body Mass Index $\geq 30 \mathrm{~kg} / \mathrm{m}^{2}$ ). The first category of questions which showed the level of snoring was confirmed from the spouses/ partners of the participants via a telephone interview with the permission of the participants. The Epworth Sleepiness Scale (ESS) contains questions concerning self-reported expectation of "dozing" in different situations, ESS scores was categorized as follows: 0 to 8 as normal, 9 to 12 as mild, 13 to 16 as moderate, and greater than 16 as severe sleepiness. Both the Berlin questionnaire and the Epworth Sleepiness Scale are validated Instruments and have been used in the Southwestern Nigeria in a similar population [7].

\subsection{Data Management}

Data collected was analyzed using Statistical Package for Social Sciences (SPSS) version 20.0 software and presented in descriptive format using tables.

\subsection{Ethical Consideration}

The study was done in accordance with the ethical standards of the institutional and national research committee and with the 1964 Helsinki declaration and its later amendments or comparable ethical standards. Ethical clearance was obtained from the Obafemi Awolowo University Teaching Hospitals Complex, Ile-Ife, Nigeria.
The consent of the participants taking part in the study was obtained.

\section{Results}

A total of 7 car parks were visited and 105 commercial car drivers were recruited into the study after considering the inclusion and exclusion criteria. All the drivers were found to be males with a mean age of $44.8 \pm 12.03$ years. A total of 49 $(46.7 \%)$ commercial drivers were said to snore. The pattern of snoring is described in Table 1. About $47 \%$ of the participants snores loudly, louder than talking and could be heard in adjacent rooms, $75.5 \%$ of them snored as frequently as more than 1-2 times a week and in $18.4 \%$ of the participants, the snoring was severe enough to cause episodes of apnoea 1-2 times a week as described by their spouses/partners. The average ESS score was 7.3 and $35.2 \%$ of the drivers had abnormal level of sleepiness. The level of sleepiness is as shown in Table 2. Sixteen (15.2\%) of the drivers reported they had fallen asleep while driving.

Table 1. Characteristics of snoring ( $N=49$ i.e. total number that snores).

\begin{tabular}{lll}
\hline Characteristics of snoring & Frequency & Percentage \\
\hline Loudness of snoring & & \\
Slightly louder than breathing & 8 & 16.3 \\
As loud as talking & 18 & 36.7 \\
As louder than talking & 15 & 30.7 \\
Very loud can be heard in adjacent rooms & 8 & 16.3 \\
Times of snoring & & \\
Nearly every day & 12 & 24.5 \\
3-4 times a week & 12 & 24.5 \\
1-2 times a week & 13 & 26.5 \\
1-2 times a month & 12 & 24.5 \\
Snoring bothered other people & & \\
Yes & 20 & 40.8 \\
No & 27 & 55.1 \\
Don't know & 2 & 4.1 \\
Notice of apnoea & & \\
Nearly every day & 2 & 4.1 \\
3-4 times a week & 2 & 4.1 \\
1-2 times a week & 5 & 10.2 \\
1-2 times a month & 7 & 14.3 \\
Never or nearly never & 33 & 67.3 \\
\hline
\end{tabular}

Table 2. Level of Sleepiness among commercial drivers.

\begin{tabular}{lll}
\hline Level of Sleepiness & No of Participants & Percentage \\
\hline Normal & 68 & 64.8 \\
Mild & 19 & 18.1 \\
Moderate & 8 & 7.6 \\
Severe & 10 & 9.5 \\
\hline
\end{tabular}

\section{Discussion}

All the commercial drivers recruited for this study were found to be males. This is probably due to the fact that in the location where the study was carried out, driving as a profession is perceived to be meant for the male sex. The mean age of the commercial drivers was $44.8 \pm 12.03$ years. This falls within the active age group. The prevalence of snoring in this study population was $46.7 \%$. This is comparable with the findings of Ozoh et al who found a 
prevalence rate of $40.4 \%$ among drivers in Lagos, Nigeria in another local study [7]. Studies from Greece and Argentina show a higher prevalent rate of $69.9 \%$ and $71 \%$ respectively $[8,9]$. This higher prevalent rate could probably be due to higher values of $28.7 \pm 3.7$ and $29.0 \pm 4.9 \mathrm{Kg} / \mathrm{m}^{2}$ respectively for their Body Mass Index (BMI) compared to $25.4 \pm 4.6$ $\mathrm{Kg} / \mathrm{m}^{2}$ obtained in this study. Increase in BMI has been shown to be a risk factor for snoring [10]. However, the prevalence of snoring seems lower in the general population compared to commercial drivers. Adewole et al found a prevalence of $31 \%$ in a general population in Abuja, Nigeria and Sogebi et al in another local study found a prevalence of $37.9 \%$ in Sagamu, Nigeria $[11,12]$. In Jordan, Khassawneh et al found a prevalence of $28.7 \%$ [13]. This wide disparity in the prevalence rate obtained in the general population when compared to what is obtained from the studies among commercial drivers shows that snoring is probably commoner among commercial drivers than in the general population. Risk factors for snoring include increasing age, sex, BMI and neck circumference $[14,15]$. The risk factors for snoring were however not part of this study. Table 1 showed that a very significant proportion of the drivers snored loudly, frequently and their snoring also bothered their spouses. This could possibly affect the sleep hygiene of their spouses and cause other possible problems associated with poor night sleep and sleep fragmentation and makes them predisposed to secondary sleep disorders [16]. Poor night sleep is associated with daytime hypersomnolence. Hence, poor night sleep can be responsible for fatigue and poor performance at work [17]. Snoring can be socially unacceptable and can cause marital disharmony and divorce [18]. It has also been demonstrated that it may also cause noise induced hearing loss among spouse/bed partners of the snorers [19]. The consequences of snoring are therefore not only found among the drivers but also on their spouses/bed partners. Episodes of sleep apnoea were noticed among the drivers and this makes them also entitled to the complications of sleep apnoea. Snoring is a feature of sleep apnoea [20]. Although, snoring is a key symptom of sleep apnoea, not everyone who snores has sleep apnoea [21].

This study showed that $64.8 \%$ of the commercial drivers had normal level of sleepiness. The remaining $35.2 \%$ had abnormal levels which ranged from mild to severe as shown in Table 2. This is high, considering the possible risk associated with sleep while driving. Driving through monotonous route daily may predispose commercial drivers to excessive sleepiness, especially during working hours. Findings from this study shows that $15.2 \%$ of the drivers admitted to the fact that they had fallen asleep while driving. This is a very significant proportion particularly in this study location where a lot of people depend on these commercial drivers for transportation. There is however paucity of comparative local data. In the United Kingdom, $20 \%$ to $25 \%$ of motorway accidents can be attributed to drivers falling asleep at the wheel [22]. This is a possible cause of road traffic accident. Road accidents are a major cause of death, and sleeping while driving has been found to affect driving skill [23]. Hence, snoring and sleepiness among commercial drivers is becoming a public health issue that needs to be addressed by government and health care providers. This can contribute to the recent increase in road traffic accidents noticed in Nigeria and possibly other parts of the world.

Assessment of sleep disorder could be done by polysomnography, Multiple Sleep Latency Test which require a sleep laboratory $[24,25]$. These were not done in this study. However, other means of assessment include use of validated instruments such as the Epworth Sleepiness Scale, Berlin questionnaire as used in this study. This provides a quick, cheap and non invasive means of assessment of these commercial drivers.

\section{Conclusion}

The prevalence of snoring among commercial car drivers was $46.7 \%$ and $35.2 \%$ of the drivers had abnormal level of sleepiness; these drivers with their passengers are at risk of road accidents. It istherefore recommended that assessment of sleep hygiene of commercial car drivers should be a pre requisite for licensure among commercial drivers.

\section{Conflicts of Interests}

All authors declare that there are no conflicts of interest.

\section{References}

[1] Macnamara M. Surgical management of snoring. In: ScottBrown's Otorhinolaryngology, Head and Neck Surgery. M. Gleeson, et al (eds). $7^{\text {th }}$. Edward Arnold Ltd: London. 2008; 2325-2339.

[2] Guyton AC, Hall JE. States of Brain Activity-Sleep; Brain Waves; Epilepsy; Psychoses. In: Textbook of Medical Physiology. $9^{\text {th }}$ edition. Philadelphia: W. B Saunders Company.1996; 761-768.

[3] Gould JB, Lee AF, James O, Sander L, Teager H, Fineberg N. The sleep state characteristics of apnea during infancy. Pediatrics. 1977; 59(2):182-194.

[4] Masa Jimenez F, Rubio González M, Findley LJ. Habitually sleepy drivers have a high frequency of automobile crashes associated with respiratory disorders during sleep. $\mathrm{Am} \mathrm{J}$ Respir Crit Care Med 2000;162:1407-1412.

[5] Ozer C, Etcibasi S, Ozturk L. Daytime sleepiness and sleep habits as risk factors of traffic accidents in a group of Turkish public transport drivers. Int J Clin Exp Med. 2014; 7(1):268-273.

[6] Dement WC. The perils of drowsy driving. N Engl J Med $1997 ; 337: 783-784$.

[7] Ozoh OB, Okubadejo NU, Akanbi MO, Dania MG. High-risk of obstructive sleep apnoea and excessive daytime sleepiness among commercial intra-city drivers in Lagos metropolis. Niger Med J. 2013; 54(4):224-229.

[8] Nena E, Tsara V, Steiropoulos P, Constantinidis T, Katsarou Z, Christaki $P$, et al. SLeep-disordered breathing and quality of life of railway drivers in greece. Chest 2008; 134(1):79-86. 
[9] Perez-Chada D, Videla AJ, O'Flaherty ME, Palermo P, Meoni J, Sarchi MI, et al. Sleep habits and accident risk among truck drivers: a cross-sectional study in Argentina. Sleep. 2005;28(9):1103-1108.

[10] Li QY, Huang SG, Li M, Liu JL, Wan HY. BMI is an independent risk factor for snoring in Chinese women aged over 30 years. Sleep Breath. 2009; 13(3): 289-293.

[11] Adewole OO, Hakeem A, Fola A, Anteyi E, Ajuwon Z, Erhabor G. Obstructive sleep apnea among adults in Nigeria. $J$ Nat Med Ass. 2009; 101(7):720-725.

[12] Sogebi OA, Oyewole EA, Soga-Peters OO. Sleep disordered breathing (SDB)experiences associated with snoring among adult Nigerians. Afr Health Sci. 2011; 11(3):309-314

[13] Khassawneh B, Ghazzawi M, Khader Y, Alomari M, Amarin Z, Shahrour B, et al. Symptoms and risk of obstructive sleep apnea in primary care patients in Jordan. Sleep Breath 2009;13(3):227-232.

[14] Knuiman M, James A, Divitini M, Bartholomew $H$. Longitudinal study of risk factors for habitual snoring in a general adult population: the Busselton Health Study. Chest 2006; 130(6): 1779-1783.

[15] Biswas RSR, Rahman MH, FazleeKibriaChowdhury Md. Relation of Snoring Habits with Body Mass Index and Neck Circumference among Adult Population. J Sleep Disord Ther 2018; 7: 293.

[16] Ulfberg J, Carter N, Talback M, Edling C. Adverse health effects among women living with heavy snorers. Health Care Women Int. 2000; 21(2): 81-90.

[17] Makowiec-Dabrowska T, Bortiewicz A, Siedlecka J, Gadzicka
E. Effects of fatique on the fitness to drive. Med Pr. 2011; 62(3): 281-290.

[18] Dille JR. Doctor Stuff- Snoring Can Be Fatal For Your Marriage And For You. Aviat Space Environ Med 1987; 58(12): 1234

[19] Sardesai MG, Tan AKW, Fitzpatrick M. Noise-induced hearing loss in snorers and their bed partners. J Otolaryngol 2003; 32(3): 141-145.

[20] Shokrollahi M, Saha S, Hadi P, Rudzicz F, Yadollahi A. Snoring sound classification from respiratory signal. $38^{\text {th }}$ Annual International Conference of IEEE Engineering in Medicine and Biology Society, Orlando 2016: pp 3215-3218.

[21] A Simple Snore or Something More? Sleep Apnea and Snoring. http://www.premierhealth.com/Women-WisdomWellness-Sleep. Accessed on 25th of December, 2018.

[22] Horne JA, Reyner LA. Sleep related vehicle accidents. BMJ 1995; 310:565-7.

[23] Aksan N, Marini R, Tippin J, Dawson J, Rizzo M. Driving Performance and Driver State in Obstructive Sleep Apnea: What Changes with Positive Airway Pressure?Proc Int Driv Symp Hum Factors Driv Assess Train Veh Des 2017; 9-15.

[24] Kushida CA, Littner MR, MorgenthalerT, Alessi CA, Bailey $\mathrm{D}$, Coleman J Jret al. Practice parameters for the indications for polysomnography and related procedures: an update for 2005. Sleep. 2005; 28: 499-521.

[25] Littner MR, Kushida C, Wise M, Davila DG, Morgenthaler T, Lee-Chiong Tet al. Practice parameters for clinical use of the multiple sleep latency test and the maintenance of wakefulness test. Sleep. 2005; 28(1): 113-121. 